\section{Corrosion and Shell Composition in Barnacles}

Ir was originally suggested by Darwin ${ }^{1}$ that the susceptibility to disintegration of the shell of the common littoral barnacle, Chthamalus stellatus (Poli), was a consequence of its high content of organic matter. This suggestion has been accepted by many authors; but there appears to be no analysis to support the contention.

The organic matter and calcium content of the shells of several common barnacles, namely, $C$. stellatus, Balanus balanoides (L.), B. crenatus Brug. and $B$. balanus (L.) Da Costa, have been determined. In each case, fifty well-formed individuals of about $10 \mathrm{~mm}$. rostro-carinal diameter were used. Chthamalus stellatus was taken from the upper level of the shore, Balanus balanoides and $B$. crenatus from mussel shells near low-tide level and $B$. balanus from material dredged at $20 \mathrm{~m}$. The soft parts were removed, and the shells thoroughly cleaned by brushing; in the case of Chthamalus stellatus it was not possible to remove all the adherent unicellular green algae. The shells were then dried at $105^{\circ} \mathrm{C}$., the inorganic material dissolved in dilute hydrochloric acid and the residual organic matter separated, washed and dried. Calcium was determined in the solution by a double precipitation as oxalate followed by titration with standard potassium permanganate solution. The results are shown in Table 1 .

Table 1

(All values as percentage oven dry material)

\begin{tabular}{|l|c|c|}
\hline \multicolumn{1}{|c|}{ Species } & \% Organic fraction & $\begin{array}{c}\text { \% Calcium as } \mathrm{CaCO}_{3} \\
\text { of inorganic fraction }\end{array}$ \\
\hline C. stellatus & $2 \cdot 1$ & $91 \cdot 1$ \\
B. balanoides & $1 \cdot 1$ & $91 \cdot 8$ \\
B. crenatus & $0 \cdot 6$ & $90 \cdot 7$ \\
B. balanus & $0 \cdot 8$ & $93 \cdot 4$ \\
\hline
\end{tabular}

It is evident that while the calcium content remains very uniform, $C$. stellatus contains a relatively larger organic content. However, when the difficulty of removing the unicellular green algae from this species is remembered it may be doubted whether the larger organic content at such a low value of the total is, per se, responsible for the increased susceptibility to corrosion. It is suggested that this is rather a function of the structure of the compartments than the quantity of organic material. Although the walls of $C$. stellatus have no parietal tubes they are permeated by numerous fine tubules. The latter are also present in the compartments of Balanus balanus (which undergoes corrosion) together with a number of small irregular pores. The presence of these tubules near the surface of the outer lamella could weaken the wall and allow corrosion to take place. In lesscorrodible species quite large parietal tubes may be present, but these are flanked by solid calcareous wall. In support of this suggestion, it may be pointed out that in some species of Tetraclita notable for their extreme corrosion, although tubules are absent, the walls are permeated by several rows of thin-walled parietal tubes so that in section the compartments have a honeycomb appearance; the solid character of the wall and its resistance to corrosion are thereby destroyed.

The Marine Station,

Millport, Scotland. Oct. 8.

H. Barnes

${ }^{1}$ Darwin, C. R., "A Monograph of the Sub-Class Cirripedia" (Ray Society, London, 1854).

\section{D morphism in the Portuguese Man-of-War}

THe Portuguese man-of-war (Physalia) occurs in two forms which are mirror images of one another but otherwise identical. Under the influence of the wind, one form (left-handed) moves to the right of the downward direction, the other (right-handed) to the left.

Woodcock ${ }^{1}$ was the first to attempt to relate these facts to wind and water movements. He observed that a large majority of specimens from the North Atlantic and Gulf of Mexico were right-handed, and sailed to the left of the downwind direction. To explain this, Woodcock formed a hypothesis which required in part that southern hemisphere forms be mirror images of northern hemisphere forms, and sail to the right of the downwind direction. An examina. tion of museum specimens seemed to show that there was, in fact, a preponderance of right-handers from the southern hemisphere (19 out of 22). Fontaine ${ }^{2}$ observed, however, that the forms driven ashore on the southern coast of Jamaica were always left-handers. The prevailing wind was from the east.

In the Canary Islands this year we observed that forms driven into the harbour at Arrecife, which lies on the eastern coast of Lanzarote, were always left. handers when the wind came from the east or northeast. On one occasion when the wind came from the south-west, right-handers were driven in.

It seems probable from Fontaine's and our own observations that the proportion in which the two forms are found varies in particular localities not according to the hemisphere but according to the position of adjacent land and the direction of the wind.

We tentatively put forward the view that in each brood of Physalia the two forms are produced in rough equality, and that this has survival value in that it obviates the stranding of the whole brood in any one set of circumstances. The early development of Physalia is little known so it is impossible to say whether or not the two forms are genetically different.

Crude experiments were made by one of us to ascertain the speed and angle of drift of Physalia. In light-to-moderate breezes the following results were obtained with the aid of a spherical glass float, a chart and landmarks inside the mole at Arrecife. Towards the end of flood-tide on April 15 the speed of drift over the tide was $20 \mathrm{~m}$. $/ \mathrm{min}$. On April 16 at slack-water the courses taken by a number of animals moving across the wind varied from $34^{\circ}$ to $42^{\circ}$ to the right of the downwind direction. A boat sailing into the wind makes more forward than lateral way, but Physalia, though pointing up to the wind, makes much lateral and slight stern way.

A. K. Totron

British Museum (Natural History), Cromwell Road, London, S.W.7.

G. O. MACKIE

Dept. of Zoology and Comparative Anatomy, University Museum, Oxford. Sept. 28 .

1 Woodeock, A. H., J. Mar. Res., 5, 196 (1944).

${ }^{2}$ Fontaine, A., Notes Nat. Hist. Soc. Jamaica, 64, 61 (1954). 